International Journal of Cultural and Religious Studies (IJCRS)

DOI: 10.32996/ijcrs

Journal Homepage: www.al-kindipublisher.com/index.php/ijcrs

\title{
Religious Radicalization: Dimension of Culture and the Foundation of Freedom
}

\author{
Mahfuzur Rahman Khan \\ Institute of Social Welfare \& Research, University of Dhaka, Bangladesh \\ $\square$ Corresponding Author: Mahfuzur Rahman Khan, E-mail: mahfuzur.rkm@gmail.com
}

\section{ARTICLE INFO}

Received: 11 September 2021

Accepted: 16 October 2021

Published: 20 October 2021

DOI: $10.32996 /$ ijcrs.2021.1.1.3

\section{KEYWORDS}

Religion, Dimensions of Culture, Freedom, Religious Radicalization.

\section{ABSTRACT}

The origins of human culture and the foundation of freedom can be traced back to the religious nature of the species. Human ability to create an entirely worldly one, separate from the great synthesis, came only after a long period of experimentation and thought. Certainly, this is seen as a positive development in the current conception of culture and its historical context. Today, it is being debated whether the detachment of human work-from science to morality to education to the state to economics to artfrom religious connections and connections has been beneficial both to culture itself and to human personality progress in the direction of higher concrete achievements and human development. The author utilized deductive reasoning to create a link between religion and the aspects of culture and the foundations of freedom in this research work, which uses a qualitative technique based on a deductive research methodology.

\section{Introduction}

Religion, freedom, and culture seem to be difficult concepts to comprehend when seen through the lens of international relations. After all, academics and philosophers have been debating the meaning of these words for decades, as well as the effect they have had on our understanding of the social environment in which we live. The first element of religion is the idea that supernatural persons and/or forces have significance to the meaning and practice of politics now and throughout history. This is the most fundamental aspect of religion. Various religious traditions approach the subject of the impact of religion on politics in a number of different ways. 'Fundamental' traditions argue that politics is a matter of organizing a society in accordance with divine instructions, which we could term a'religious' tradition. The current religious radicalization described as "fundamentalism" in the sphere of different political cultures does not seem like simple more "observant" return to traditional religiosity. Often, this radicalization has the connotation of a specific reaction to the liberal conception of the modern state, due to its ethical relativism and its indifference to religion. On the other hand, many criticize the liberal state for the opposite reason, that is, for the fact that its proclaimed neutrality does not seem capable of avoiding the tendency to consider the profession of faith and religious membership as an obstacle to admission. to the full cultural and political citizenship of individuals. It could be said that we are dealing with a form of "morbid totalitarianism" that makes us especially vulnerable to the spread of ethical nihilism in the public sphere. Culture would be subjected to the pure point of view of critical objectivity at this point in time. The operating spirit would now be solely focused on the object at hand, and it would be possible to achieve the highest possible level of operational efficiency. A free culture would thus emerge in its own essence, bound only by its own criteria, which would be referred to as an autonomous culture. And, on an equal level, humanity as the originator of culture, which corresponds to it. As a result, man would be free of any ties that aren't derived from the things themselves; he'd be able to form his own opinions, take his own initiatives, and mature as a self-sufficient creator. According to this conception, any objective religious bond would pose a threat to freedom because it would bind the creative personality to an instance outside of its own operational field, thereby limiting its ability to innovate. The work would fall under the category of equivocal points of view, and the operator would be ambiguous as a result. When thoroughly considered, such a conception has the unintended consequence that even the most subjective religious bonds endanger the autonomy of the individual. The reason for this is that, even if a religious element possesses the characteristics that have been described thus far, it is foreign to the immediate worldly reality and can only have an impact on it by causing consternation. Positivism, in all of its manifestations, ultimately leads to the conclusion that all religious elements must be eliminated from human

Copyright: (c) 2021 the Author(s). This article is an open access article distributed under the terms and conditions of the Creative Commons Attribution (CC-BY) 4.0 license (https://creativecommons.org/licenses/by/4.0/). Published by Al-Kindi Centre for Research and Development, London, United Kingdom. 
life and action. When the issue of religious freedom arises in any part of the world today, it is discussed in relation to a conception of human rights and civil liberties that is associated with a liberal, democratic, pluralistic, and secular political culture, whether in a positive or negative way. The language of the modern liberal state expresses the humanistic rhetoric that appeals to the values of peaceful coexistence, individual dignity, intercultural and interreligious dialogue, as well as the values of interfaith and intercultural dialogue. In addition, it draws on the Christian principles of the dignity of person and brotherhood among men, which have both contributed to the formation and universalization of that language, to a greater extent than before. Within the context of today's political cultures, religious radicalization, also known as "fundamentalism," does not appear to be a simple return to traditional religiosity with greater "observance." This radicalization is frequently characterized by a specific reaction to the liberal conception of the modern state, which is characterized by its ethical relativism and indifference to religious beliefs, among other characteristics. For many, on the other hand, the liberal state appears to be criticized for the opposite reason: that is, for the fact that its proclaimed neutrality does not appear to be able to prevent the tendency to regard professed faith and religious affiliation as a barrier to the acceptance of individuals as fully participating members of society in terms of culture and politics.

\section{Literature Review}

Despite the universalist viewpoint on spirituality, individuals experience and express spirituality in a variety of ways depending on their social and cultural worldviews, which are made up of attitudes, values, ideas, and life philosophies. Toward one end of the scale, innovation might be viewed as a danger to "regular" methods of being and acting human, or as a force that humans can't control (Khan, 2020a). In contrast, a religiosity emerges from here that withdraws more and more from the fields of cultural life, eliminates all worldly content from its world, becomes "more interior," but at the same time becomes poorer and more inert as a result of this withdrawal. When practices are classified as "religious," they typically enjoy greater legal protection from state interference than when they are classified as "cultural" (Earp, 2015). Strong political, monetary, and social changes enable social orders to experience a significant advancement in strategic mindsets. When combined with the seriousness of a mechanical turn of events and the capacity to absorb increasingly current methods, these changes enable managers to provide a strategic vision to predict the eventual fate (Khan, 2020b). The Kluckhohn model for worldviews, for example, offers a framework for comprehending cultural values as a basis for religion and as manifestations of spirituality in a cultural context (Fukuyama $\&$ Sevig, 1999; Fukuyama, Siahpoush, \& Sevig, 2005). According to historical religions, many phenomena associated with their re-emergence in the political and social spheres appear to be completely incompatible with the authentic tradition and cultural development of their respective religions, if not outright contradictory. A significant reason for the inclusion of "freedom of religion" as a legal right is the reverence with which religion or belief is held. As philosopher Martha Nussbaum puts it, "the ability to seek an understanding of the ultimate meaning of life in one's own way is one of the most essential characteristics of a truly human life and historically, one of the most common ways of accomplishing this has been through religious belief and practice; burdening these practices thus inhibits many people's search for the ultimate good" (Nussbaum, 2001). For believers themselves, new forms of religiosity, cultivated in the wake of arbitrarily contaminated boundaries between the pursuit of psychophysical well-being and pseudo-scientific constructions of the world and of the self, appear as disturbing deviations from traditional religious orientation. Individual conscience, or the freedom to believe and express one's beliefs publicly, is regarded as critical for the survival of democracy (Trigg, 2013).

Let alone the religious motivations of some forms of totalitarian fanaticism, which seek to impose terrorist violence even within the great religious traditions, which are based on a crude religious interpretation. Many (particularly young people) believe that it is justified for them to enter a desperate fanaticism, whether atheistic or even theocratic, in response to the system's humanistic failings. Those who are drawn to violent and totalitarian forms of political ideology or religious militancy, which had previously appeared to be beyond the reach of reason and history, must reexamine their motivations in a new light and with greater depth of analysis. Emile Durkheim (Durkheim \& Swain, 2008), for example, emphasizes that religion is eminently social in nature, providing people with social cohesion, control, and purpose, as well as opportunities for interaction and reaffirmation of social norms. Religious practices typically involve the use of culturally prescribed means to make contact with or gain access to these powers, and the means of contact or access vary according to the religious imagination and the social and cultural forms of accessibility (Riesebrodt, 2010). Decent society was undoubtedly born from this pragmatism of a part of the elites, which little by little converted to the questioning of an understanding of individual freedom which reduced it to equal rights and which affirmed that political inequalities were the natural and necessary consequence of the latter (Khan, 2021).

\section{Methodology}

This research paper employs a descriptive research technique based on a deductive research approach, as the author used deductive logic to establish a connection between religion and the dimensions of culture and the foundations of freedom. The formulation of descriptive concepts of reality does not help at all if this partial vision of it is not complemented by an analysis that contributes to the change of reality itself, and the world of duty to be (Khan \& Sultana, 2021). To define and measure the level of influence of various intermediate variables, future research can put forward hypotheses based on the model and conduct an empirical analysis to demonstrate its value in practical applications (Khan, 2020b). Due to the fact that deductive reasoning is applied to proceed from the specific to the universal. If a causal relationship or link appears to be inferred by a particular theory 
or case example, it is possible that it is true in many circumstances, and deductive design can be used to establish whether this relationship or link existed under more general conditions. Individuals establish a hypothesis (or research hypotheses) based on existing theory and then design an inquiry method to test the hypothesis using a logical technique (Wilson, 2014).

\section{Religion as Dimension of Culture}

When people define culture in broad terms, people may suppose that religious culture is a subset of culture as a whole, with meanings that overlap but are distinct from other subsets like educational culture, entertainment culture, economic culture, political culture, and media culture. The author looked at religion and culture from a personal, national, and worldwide viewpoint, and provided many short instances. Religion and culture have an impact on international relations in unique ways that have been highlighted, yet there are obvious connections between the two concepts. These kinds of connections have been made by theorists for a long time and are relevant to our current discussion. There are several striking parallels in this chapter's discussion of religion and culture, such as the importance placed on symbols and tales in both, and the desire for a better quality of life-based on one's faith or culture. Consider whether international relations should treat "culture" as the overarching concept, with "religion" as a subgroup within it. This is an important issue. This point of view makes sense, given that no one religion now covers a whole civilization, and no culture follows a single set of holy laws and rituals in their entirety. Some cultures place more value on religious identity and authority, while others do not. Religion is as important, if not more so than culture in each of these instances. So maybe the best approach is to view religion and culture as two sides of the same coin that are always in conversation with one another. With regard to the man himself, the fear that he is losing, so to speak, specific weight, of personal-human validity, grows more and more intense with each passing day. For those concerned with individual liberties, there's a disconcerting fact to consider, one that is becoming more and more evident with time: man is at the mercy of his own actions. Despite the fact that he has destroyed religious bonds in order to achieve complete self-mastery over his own action and disposition of the world, the resulting work has become autonomous and has reduced man to the level of his own function. The process manifests itself in a politicalsocial expression in a society or in a state that gradually eliminates individual initiative and reduces man to the status of a tool for the pursuit of personal goals. There is a subtle logic at work here, one that modern man has not yet fully grasped or comprehended. In recent years, the conviction has gained ground that the element of existence from which modern man has freed himself for the sake of his personal freedom and work is actually a necessary prerequisite for him to be truly free and lord of himself, as well as for him to be able to perform work that can provide him with an awareness of authentic meaning. Religions of the world's great religious traditions are no longer seen as the remnants of ancient epochs and pre-modern cultures that have been overtaken by history. Diverse forms of religious affiliation have a new impact on the formation of personal identity, on the interpretation of social bonds, and on the search for the common good, among other things. Even in many secularized societies, the various forms of the religious community are still socially perceived as important factors in the intermediation of relations between individuals and the government. When it comes to the current configuration of these models, the relatively new element can be identified in the fact that today, the relevance of religious communities is committed to positioning themselves directly or indirectly towards the democratic-liberal model of the rule of law and the techno-economic direction of civil society.

\section{Religion as the Foundation of Freedom}

When the right to religious or philosophical freedom is mentioned, the first thing that comes to mind is the right of individuals to act in accordance with their conscientious beliefs, to worship (or not worship) freely, and to enjoy life in society without facing discrimination on the basis of such beliefs. However, in practice, the enjoyment of these fundamental religious freedom rights is critically dependent on the legal structures available to religious communities to organize their affairs. There are numerous examples throughout history of laws that impose restrictions on individual religious practices by denying legal recognition to certain religious organizations. Despite claims of ideological neutrality, a political culture that aspires to establish purely procedural rules of justice, removing all ethical justification and any religious inspiration from the process, demonstrates a proclivity to develop an ideology of neutrality that in practice imposes the marginalization, if not the exclusion, of religious expression from the public square. As a result, from complete freedom of participation to the formation of democratic citizenship is the path to take. It is for this reason that there is ambivalence between the only apparent neutrality of the public sphere and an objectively discriminating civil libertarian freedom. The emergence of religious pluralism places institutions in the face of everyday cases involving the concreteness of the personal and family lives of citizens, as well as cases involving the community that stand out for their novelty as well as for the common characteristic of having their origins in religious affiliation. The need to protect religious freedom may arise even in situations that are considered to be part of the ordinary dimension of human life, such as nutrition and (however tragically) burial, or in situations that are considered to be extraordinary circumstances (such as confinement in a prison), and you may find yourself in this situation. It is well understood that the spiritual dimension touches deep chords of personal and, for many, community identity, as well as the claim of space and rights and that when operated by "others," it moves a reactivity that is both paradoxical and profoundly at odds with the very premises on which the reactions are based. The institutions that are closest to the citizens, and in particular the municipalities, are called upon to play a fundamental role in the dissemination of knowledge, the normalization of situations, and the integration of the various souls of citizenship that reside within their respective jurisdictions. The nature of this role necessitates that it be enlightened, and the principles and constitutional guarantees that serve as a 
framework and condition for peaceful coexistence while also being sensitive to the deepest needs of individuals, women, families, and the social communities in which they live serve as a starting point for this enlightenment. Wherever the problem of religious freedom arises in the world today, this concept is discussed in reference (whether positive or negative) to a conception of human rights and civil liberties that is associated with a liberal, democratic political culture., pluralistic and secular. A value-based subjective conceptualization of human dignity, equality, and freedom, framed around the commonwealth, potentially fulfills the standard of sufficiency (Khan, 2021). The humanist rhetoric that appeals to the values of peaceful coexistence, individual dignity, intercultural and interreligious dialogue is expressed in the language of the modern liberal state. On the other hand, and even more profoundly, it is based on the Christian principles of the dignity of the person and of the proximity between men, principles that have contributed to the formation and universalization of this language.

\section{Results and Discussion}

Culture and the foundations of freedom can be defined as constructively created behaviors based on collective beliefs that reflect patterns of thinking, feeling, acting and reacting, values, and other meaningful systems for people, thus separating one group of people from another with a general preference for certain states of affairs and values over others. These beliefs and values are typically transmitted via the cultural succession principle and collective mind programming. Thus, it is necessary to understand humans and their systems within a cultural and ethnic context, which necessitates a multicultural or culture \& foundations of freedom-embedded perspective that attempts to reconcile universalism and relativism by explaining behavior and values in terms of both culturally learned perspectives that are unique to a particular culture and the search for shared universals. By defining culture $\&$ foundations of freedom in such broad terms and by understanding humans in a cultural context, authors can assume that religion can subset culture $\&$ foundations of freedom in general, with meanings that overlap with but are distinct from those of other subsets. Thus, religion can be defined as a system of collective beliefs in divine power and worship practices directed toward that power. Religion as a cultural system of symbols and values contributes to the establishment of communal, pervasive, and long-lasting motivations and behaviors that express an individual's innate desire for a connection with a transcendental reality. As a result, many of the variations in the expression of religiosity and spiritual experience stem from cultural influences. That is distinctive characteristics of religiosity center on the richness, values, and beliefs inherent in particular cultural content. In other words, dimensions of culture $\&$ foundations of freedom establish a social mechanism for sustaining the type of religiosity that is acceptable to a group of people and can be practiced collectively within a given cultural context, thereby classifying religion to a subset of the dimensions of culture $\&$ foundations of freedom.

\section{Conclusion}

In contrast to the classical thesis, which foresaw the reduction of religion as an inevitable effect of technical and economic modernization, today there is talk of a return of religion to the public stage. To tell the truth, this automatic correlation between civil progress and the extinction of religion had been formulated according to an ideological prejudice that saw religion as the mythical construction of a human society that was not yet the owner of the rational instruments capable of producing emancipation and freedom \& welfare of society. This scheme proved inadequate, not only in relation to the true nature of religious consciousness but also in relation to the naive confidence placed in the humanizing effects of the mod. In this dialectical framework, we could briefly summarise the anthropological approach of the conciliar document. Dignitatis Humanae establishes the radical link between the inviolable rights of man - and, therefore, his individual freedom - and the very nature of his being-person. In fact, there is only one criterion for the effective recognition of the personal a priori: biological belonging to the human race. Personal dignity and inherent human rights are already unconditionally reflected in this membership. The being-person, in this sense, is not an attribution related to a specific quality or endowment of the human being, such as his conscious being or his capacity for selfdetermination. Nor is it a potentiality or effect of his maturation. Personal dignity is radically inherent to the individual, as a constitutive factor of his human condition: it is the matrix of every individual quality, of every existential condition, of every degree of development. Personal existence evolves and develops, certainly; being-person, however, is not something that anyone can add to himself (or to another). There is no process of the human being in which "something" becomes "someone": being-human and being-person one is always and indivisible because one does not become human if one is something else. And the human way of being is that of being personal individuality. The differences and similarities between different contexts of empirical reality must be identified from a historical perspective, but also an intercultural one (Khan \& Sultana, 2021). The alleged ideological neutrality of a culture that one wants to build from the elaboration of merely procedural rules of justice, which dispense with all ethical justification and all religious aspirations, shows the tendency to elaborate an ideology of neutrality that, in fact, it imposes the marginalization, if not the exclusion, of religious expressions from the public sphere and, therefore, of full freedom of participation in the formation of democratic citizenship. The ambivalence of the public sphere's ostensibly neutral neutrality and objectively discriminatory civil liberties is exposed here. A civil culture that defines its humanism through the suppression of the religious component of the human being is forced to also eliminate decisive parts of its own history, its own knowledge, its own tradition, and its social cohesion. The result is the suppression of increasingly important parts of humanity and citizens that make up that society. The reaction to this humanistic weakness of the system even makes it seem justified in the eyes of many (especially young people) to lead to a desperate fanaticism that can be both atheistic and theocratic. The incomprehensible attraction exerted by 
some violent and totalitarian forms of political ideology or religious militancy, which seem relegated to the judgment of reason and history, must challenge us in a new way and make us go even deeper in our analysis.

\section{References}

[1] Durkheim, E., \& Swain, J. W. (2008). The elementary forms of religious life. Courier Corporation.

[2] Earp, B. D. (2015). On the supposed distinction between culture and religion: A brief comment on Sir James Munby's decision in the matter of $B$ and $G$ (children). Practical Ethics. The University of Oxford. Available at: http://blog. practical ethics. ox. ac. UK/2015/02/on-the-supposeddistinction between-culture-and-religion-a-comment-on-sir-James-munbys-decision in-the-matter-of-b-and-g-children.

[3] Fukuyama, M. A., \& Sevig, T. D. (1999). Integrating spirituality into multicultural counseling (Vol. 13). Sage Publications.

[4] Fukuyama, M. A., Siahpoush, F., \& Sevig, T. D. (2005). Religion and Spirituality in a Cultural Context.

[5] Khan, M. M. R. (2020a). Rationalizing the Relationship between Ergonomics and Human Resource Management. Journal of Mechanical, Civil and Industrial Engineering, 1(1), 31-35.

[6] Khan, M. M. R. (2020b). Strategic human resource management in facilitating the organizational performance: Birds-eye view from Bangladesh. Annals of Management and Organization Research, 2(1), 13-24.

[7] Khan, M. M. R. (2021). Political state and the dilemma of dignity, equality, and freedom: Evidence from a sovereign state. Dynamics of Politics and Democracy, 1(1), 29-37.

[8] Khan, M. M. R., \& Sultana, R. (2021). The shift in the role of criminology in criminal law: Reflecting the doctrinal change. Annals of Justice and Humanity, 1(1), 1-10.

[9] Nussbaum, M. C. (2001). Women and human development: The capabilities approach (No. 3). Cambridge University Press.

[10] Riesebrodt, M. (2010). The promise of salvation: A theory of religion. University of Chicago Press.

[11] Wilson, J. (2014). Essentials of business research: A guide to doing your research project. Sage 